
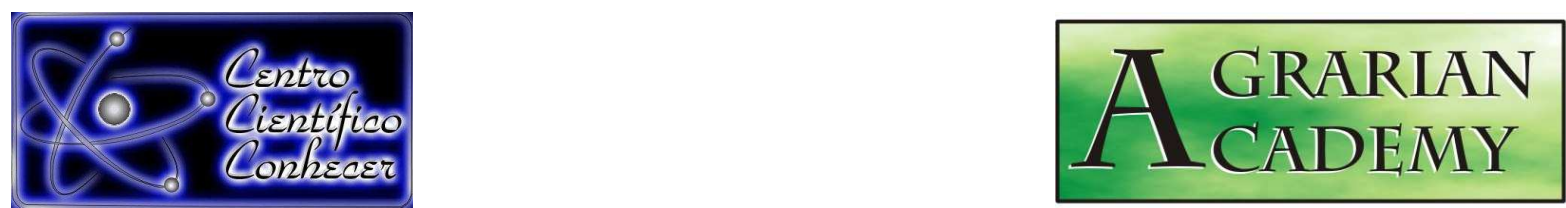

\title{
TERMOGRAFIA POR INFRAVERMELHO COMO FERRAMENTA DE DIAGNÓSTICO PRECOCE DE ESTRESSE HÍDRICO SEVERO EM SOJA
}

\author{
${ }^{1}$ Gustavo Francisco Rosalin Saraiva, ${ }^{1}$ Regina da Silva Andrade, ${ }^{1}$ Gustavo Maia \\ Souza \\ ${ }^{1}$ Universidade do Oeste Paulista (UNOESTE), Laboratório de Inteligência em Plantas \\ e Ecofisiologia "Ulrich Luttge" - LIPEUL, Presidente Prudente-SP. \\ E-mail: saraivaunoeste@hotmail.com
}

Recebido em: 05/12/2014 - Aprovado em: 14/12/2014 - Publicado em: 15/12/2014

\begin{abstract}
RESUMO
A água participa de todos os processos fisiológicos e bioquímicos das plantas, sendo responsável entre outras coisas pela regulação térmica da planta. Em condições de alta radiação e déficit hídrico a transpiração é reduzida, devido ao fechamento estomático, aumentando o risco de a temperatura da folha aumentar acima de um limiar ótimo para a atividade metabólica, levando a irreversíveis danos oxidativos nos tecidos. O objetivo desse trabalho foi verificar a hipótese de que imagens térmicas podem fornecer um diagnóstico precoce de estresse hídrico severo. Plantas de soja tiveram sua irrigação suspensa por oito dias, em ambiente controlado. Foram avaliadas: a fluorescência da clorofila, temperatura foliar (imagens térmicas) e análise bioquímica, sendo os resultados comparados com plantas mantidas sob irrigação normal. Os resultados apontaram inicio de estresse bioquímico e de fotoinibição ao final do período de suspensão de irrigação. Contudo as imagens térmicas mostraram diferenças significativas entre os tratamentos a partir de três dias sem irrigação. Os dados comprovam a eficácia de imagens térmicas como ferramenta para monitorar com antecedência estresse hídrico severo em plantas de soja.
\end{abstract}

PALAVRAS-CHAVE: Estresse oxidativo, Glycine max, imagens térmicas

\section{INFRARED THERMOGRAPHY AS A TOOL TO EARLY DIAGNOSTIC OF SEVERE WATER STRESS IN SOYBEAN}

\begin{abstract}
Water participates in all physiological and biochemical processes in plants and is responsible among other things for the thermal regulation of the plant. In high radiation and water deficit conditions transpiration is reduced due to stomatal closure, increasing the risk of leaf temperature increases above a great threshold for metabolic activity leading to irreversible oxidative tissue damage. The aim of this study was to verify the hypothesis that thermal imaging can provide an early diagnosis of severe water stress. Soybean plants had their irrigation suspended for eight days in a controlled environment. We have measured the fluorescence of chlorophyll, leaf temperature (thermal imaging) and biochemical analysis, and the results compared with maintained at normal irrigation plants. The results showed early biochemical stress and photoinhibition at the end of the irrigation period of suspension. However thermal imaging showed significant differences between treatments from three days without irrigation. The findings support the efficacy of
\end{abstract}


thermal imaging as a tool to monitor in advance severe water stress in soybean plants.

KEYWORDS: Glycine max, thermal imaging, oxidative stress

\section{INTRODUÇÃO}

Devido ao grande potencial para produção e consumo em larga escala, a soja (Glycine max (L.) Merrill) é um importante produto agrícola mundial. No entanto, essa cultura enfrenta problemas em várias regiões onde o cultivo pode ser limitado pelas condições climáticas, como: elevadas temperaturas, baixa precipitação média anual e baixa capacidade de retenção de água no solo (FRANCHINI et al., 2009). A falta de água, e consequente estresse hídrico na planta, podem causar grandes impactos na produtividade da soja, havendo registros de redução de até $50 \% \mathrm{em}$ várias partes do mundo. Sob condições de estresse, as plantas apresentam uma série de mudanças morfológicas, fisiológicas e bioquímicas, que afetam negativamente a produção de óleo e enchimento de grãos (LISAR et al., 2012; SOUZA et al., 2013). Considerando que dois terços da produção mundial de alimentos são cultivados em condições de falta de água, este passa a ser o principal fator de limitação da produção mundial de soja (BOARD, 2013).

A água participa de praticamente todos os processos fisiológicos e bioquímicos das plantas, compondo aproximadamente $90 \%$ de sua biomassa total. Ela é responsável, entre várias outras funções, pela regulação térmica da planta, agindo na manutenção da homeostase térmica e promovendo suporte mecânico para o crescimento (FARIAS et al., 2007). Dependendo de condições ambientais, diferentes níveis de limitação de água podem ocorrer. O déficit hídrico pode ser moderado, causando fechamento estomático e redução das trocas gasosas, o que, potencialmente pode levar a rupturas nas estruturas celulares e, eventualmente, a uma interrupção nas reações metabólicas (JALEEL et al., 2009).

Um dos mais importantes parâmetros fisiológicos afetados pela seca ou déficit hídrico é a fotossíntese, devido à progressiva redução na assimilação de $\mathrm{CO}_{2}$. Essa diminuição na taxa fotossintética é associada primeiramente ao fechamento estomático induzido pelo declínio no turgor celular das folhas que limitam a difusão do $\mathrm{CO}_{2}$ na câmara subestomática. Sob condições que reduzem a difusão do $\mathrm{CO}_{2}$ através do mesofilo, pode ocorrer a fotoinibição, um processo que reduz 0 rendimento quântico do PSIl e induz a fotorrespiração e a produção de $\mathrm{H}_{2} \mathrm{O}_{2}$ (HOSSAIN et al. 2009).

A produção de espécies reativas de oxigênio (ROS) é uma das principais respostas às perturbações ambientais, sendo a fotossíntese um dos processos fisiológicos mais sensíveis ao acúmulo de ROS. Seu aumento pode causar dano celular, mas também pode atuar como mecanismo de sinalização e comunicação em plantas (KIRAKOSYAN et al., 2009). Uma produção maciça de ROS, não controlada pelos mecanismos antioxidantes, pode induzir redução dos pigmentos fotossintéticos, degradação das membranas do tilacóide, e alteração na estrutura e função de proteínas. As plantas respondem ao estresse oxidativo através da regulação do balanço da produção de compostos e enzimas antioxidantes (URANO et al., 2009).

O controle da abertura estomática resulta de alterações coordenadas no turgor das células-guarda, dependentes do fluxo de íons, mudanças no citoesqueleto, transporte de membrana e expressão gênica. Essa regulação envolve a ocorrência de diferentes sinais de coordenação das redes metabólicas, resultando em uma modulação da abertura estomática refinada e rápida, em resposta á 
flutuações ambientais (HETHERINGTON \& WOODWARD, 2003). Em condições de déficit hídrico a transpiração é reduzida devido ao fechamento estomático, podendo ocasionar aumento da temperatura foliar acima de um limiar ótimo para a atividade metabólica. Estudos têm evidenciado que há uma grande relação entre a temperatura foliar e estresse em plantas (MELOTTO et al., 2008), possibilitando o surgimento e utilização de diversas técnicas para monitorar o estado fisiológico das culturas.

Dentre as diversas técnicas de sensoriamento remoto, a imagem térmica (Termografia) tem sido utilizada com grande potencial nas ciências agronômicas e ambientais, e também na agroindústria alimentícia (MAES \& STEPPE, 2012). Imagens térmicas podem mostrar diferenças entre plantas irrigadas e não irrigadas e até mesmo diferentes intensidades de irrigação (ZARCO-TEJADA et al., 2012). Em alguns casos, uma simples imagem pode ser suficiente para revelar variações espaciais no estado hídrico das plantas (PADHI et al., 2012). O sensoriamento remoto está na base da horticultura de precisão, que visa fazer uso mais eficiente dos recursos disponíveis, para aumentar a produtividade, e minimizar os impactos ambientais (FEDOROFF et al., 2010; LEE et al., 2010).

Devido a grande sensibilidade dos modernos equipamentos de termografia por infravermelho, trabalhou-se com a hipótese de que este tipo de ferramenta possa permitir um diagnóstico precoce do estresse hídrico severo em plantas de soja, uma vez que existe uma grande correlação entre temperatura foliar e conteúdo de água na planta (BERNI et al., 2009), processos de dissipação de calor (SOUZA et al., 1999), e atividade metabólica de forma geral (KUMAR, 2009).

O objetivo deste trabalho foi testar a hipótese de que as imagens térmicas permitem um diagnóstico antecipado de estresse hídrico severo em plantas de soja em regime de suspenção de irrigação.

\section{Ambiente do Experimento}

\section{MATERIAL E METODOS}

O Experimento foi realizado em estufa climatizada do tipo "Fitotron" (ELETROLABß), localizada no Laboratório de Inteligência em Plantas e Ecofisiologia "Ulrich Lüttge" (LIPEUL), na Universidade do Oeste Paulista (UNOESTE), Município de Presidente Prudente - SP. A temperatura ao longo do experimento foi mantida em $21 \pm 0,08^{\circ} \mathrm{C}$ durante a noite e $29 \pm 0,27^{\circ} \mathrm{C}$ durante $\mathrm{o}$ di a, com fotoperíodo de 14 horas de luz e 10 de escuro. A densidade de fluxo de fótons fotossintéticos (DFFF), mantida em 500 umols $\mathrm{m}^{-1} \mathrm{~s}^{-1}$, foi medida com um quantômetro (modelo Li-190SA) acoplado a um leitor digital (modelo Li-250A, Li-Cor, EUA).

\section{Material Vegetal}

Sementes de soja (Glicine max, cv. Potência) germinaram no Fitotron em vasos contendo $2 \mathrm{Kg}$ de areia lavada, seca e pesada. Os vasos $(n=30)$ foram mantidos em capacidade máxima de retenção de água durante a germinação e desenvolvimento inicial das plântulas. As plantas eram irrigadas diariamente, no período da manhã, com $100 \mathrm{~mL}$ de solução nutritiva "Hoagland". O volume da irrigação foi determinado após pesagem dos vasos com sua capacidade máxima de retenção de água e verificação da perda diária por evapotranspiração.

\section{Tratamentos}

Aos 21 Dias Após Emergência, as plantas se encontravam no inicio do estádio fenológico denominado V4. A partir dessa fase, 15 vasos foram mantidos com 
irrigação constante sendo o tratamento controle (CO) e outros 15 vasos tiveram sua irrigação suspensa (IS) por oito dias, sendo posteriormente re-irrigadas para recuperar a hidratação das plantas. No momento anterior ao retorno da irrigação os vasos com irrigação suspensa apresentavam em média $10 \%$ da capacidade máxima de retenção de água, verificada pelo peso dos vasos em comparação aos vasos do tratamento controle.

\section{Fluorescência da Clorofila}

Foi estimada a eficiência quântica potencial do FSII (Fv/Fm) em dois momentos distintos: Logo pela manhã, antes de iniciar o período de luz ("pre-dawn") e ao meio dia (12:00 h). Utilizou-se para isso um medidor portátil de emissão de fluorescência da clorofila a (modelo FlourPen-FP100, Photon Systems Instruments, $\mathrm{Cz}$ ) que aplicava um pulso de luz saturante de $3000 \mu \mathrm{mol}\left(\right.$ photon) $/ \mathrm{m}^{2}$ por um segundo $(F m)$, precedido por $200 \mathrm{~ms}$ de escuro $\left(F_{0}\right)$. Nas medidas do meio dia as plantas foram deixadas por meia hora no escuro, para permitir a completa aclimatação e redução total dos componentes dos fotossistemas. Foram utilizadas oito plantas por tratamento para realização das medidas utilizando as mesmas folhas nos dois horários de medidas.

\section{Imagens Térmicas}

Foi utilizada a câmera de imagens térmicas por infravermelho (modelo E5, FLIR) para obtenção das imagens térmicas. As temperaturas médias do solo e das plantas de soja foram aferidas diariamente durante o período de suspensão da irrigação, pela utilização das imagens. As imagens foram feitas em 10 plantas sempre as 12:00 h. As imagens foram analisadas pelo software "FLIR Tools", onde foram determinadas as temperaturas médias da planta e do solo. Para tanto, foram utilizados 10 pontos em cada planta e outros 10 no solo para determinar as temperaturas médias e gerar os dados para análise estatística, pois cada pixel da imagem corresponde a uma temperatura, segundo o software.

\section{Análise Bioquímica}

Para as análises bioquímicas, foram coletadas folhas durante o período da suspensão da irrigação até o dia de retorno da re-irrigação. As coletas foram realizadas as 12:00 h. Após a coleta, as folhas foram embrulhadas em papel alumínio e sacos plásticos, sendo posteriormente imersas em nitrogênio líquido e armazenadas em ultra freezer $a-80^{\circ} \mathrm{C}$. A obtenção d o extrato bruto se deu através da re-suspensão do material vegetal processado (300 mg) em 10,0 mL de tampão fosfato de potássio $0,1 \mathrm{M}$ com pH 6,8. Após a maceração as amostras foram colocadas para centrifugar por 10 minutos a $10000 \mathrm{rpm}$, sendo então, o sobrenadante coletado em microtubos e armazenado em ultra freezer a $-80^{\circ} \mathrm{C}$. Para a quantificação da atividade enzimática, primeiramente foi determinado o Teor de proteínas solúveis, de acordo com BRADFORD (1976). Os valores de proteína encontrados foram utilizados no cálculo da atividade das enzimas de estresse. Foram determinadas as atividades das enzimas: Superóxido Dismutase (SOD), de acordo com a Técnica de BEAUCHAMP \& FRIDOVICH (1971), citado por BOR et al. (2003); Peroxidase (POD), de acordo com as condições citadas no trabalho de TEISSEIRE \& GUY (2000); e também da Catalase (CAT), de acordo com o trabalho de PEIXOTO et al. (1999).

\section{Análise Estatística}


Para análise estatística dos dados, todos os resultados obtidos foram submetidos à análise de variância (teste $F$ ), e então as médias foram comparadas pelo teste Tukey a $5 \%$ de probabilidade, utilizando o programa de computador ASSISTAT ${ }^{\circledR}$.

\section{RESULTADOS E DISCUSSÃO}

Informações sobre mudanças na eficiência fotoquímica potencial e na dissipação de calor pelas plantas podem ser obtidas pelas técnicas de medidas de fluorescência da clorofila que utilizam medidores portáteis (MAXWELL \& JOHNSON, 2000). Esses atributos fisiológicos podem indicar o quanto o estresse ambiental afeta o metabolismo vegetal. Nesse trabalho foi verificado que a eficiência quântica potencial do FSII (Fv/Fm) medida no "pre-dawn" apresentou redução significativa nas mudas em IS apenas no dia um após o retorno da irrigação (1DRE). Já as medidas realizadas ao meio-dia mostraram que a partir de 3DSI, as plantas em IS apresentavam valores de Fv/Fm significativamente menores que as plantas controle, seguindo uma tendência de diminuição até o fim do experimento (Tabela 1). Esses resultados indicam que as mudas em suspensão de irrigação apresentaram fotoinibição dinâmica do aparelho fotoquímico devido à falta de água, pois os valores de Fv/Fm apresentavam diminuição ao meio-dia mas apresentaram posterior recuperação durante a noite, até 8DSI.

TABELA 1: Eficiência Quântica Potencial do FSII (Fv/Fm), medidas com fluoromêtro portátil, no período "pre-dawn" e as 12:00 h. Avaliações realizadas no período de 13 a 22 de março de 2014. CO: mudas com irrigação constante; IS: mudas em suspensão de irrigação.

Pre-dawn 12:00 h

\begin{tabular}{lcccc} 
& CO & IS & CO & IS \\
\cline { 2 - 5 } $0 \mathrm{DSI}$ & $0,79 \mathrm{a}$ & $0,79 \mathrm{a}$ & $0,79 \mathrm{a}$ & $0,79 \mathrm{a}$ \\
$1 \mathrm{DSI}$ & $0,79 \mathrm{a}$ & $0,79 \mathrm{a}$ & $0,79 \mathrm{a}$ & $0,79 \mathrm{a}$ \\
$2 \mathrm{DSI}$ & $0,78 \mathrm{a}$ & $0,79 \mathrm{a}$ & $0,78 \mathrm{a}$ & $0,76 \mathrm{a}$ \\
$3 \mathrm{DSI}$ & $0,78 \mathrm{a}$ & $0,79 \mathrm{a}$ & $0,79 \mathrm{a}$ & $0,74 \mathrm{a}$ \\
$4 \mathrm{DSI}$ & $0,79 \mathrm{a}$ & $0,79 \mathrm{a}$ & $0,79 \mathrm{a}$ & $0,70 \mathrm{~b}$ \\
$5 \mathrm{DSI}$ & $0,79 \mathrm{a}$ & $0,78 \mathrm{a}$ & $0,78 \mathrm{a}$ & $0,70 \mathrm{~b}$ \\
$6 \mathrm{DSI}$ & $0,79 \mathrm{a}$ & $0,79 \mathrm{a}$ & $0,79 \mathrm{a}$ & $0,68 \mathrm{~b}$ \\
$7 \mathrm{DSI}$ & $0,78 \mathrm{a}$ & $0,78 \mathrm{a}$ & $0,79 \mathrm{a}$ & $0,65 \mathrm{~b}$ \\
$8 \mathrm{DSI}$ & $0,77 \mathrm{a}$ & $0,78 \mathrm{a}$ & $0,79 \mathrm{a}$ & $0,63 \mathrm{~b}$ \\
$1 \mathrm{DRE}$ & $0,78 \mathrm{a}$ & $0,75 \mathrm{~b}$ & $0,78 \mathrm{a}$ & $0,67 \mathrm{~b}$
\end{tabular}

${ }^{*}$ Médias seguidas da mesma letra não diferem significativamente entre os tratamentos (CO e IS), a $5 \%$ de probabilidade, segundo teste Tukey. DSI: Dias Sem Irrigação, DRE: Dia da Re-irrigação.

No final do experimento, as mudas em irrigação suspensa apresentavam inicio de fotoinibição crônica, quando os valores de $\mathrm{Fv} / \mathrm{Fm}$ não apresentaram recuperação durante a noite, evidenciando um dano mais severo no FSII. A danificação do aparato fotossintético ocorre devido à foto-oxidação das proteínas $D$ do fotossistema II, que são localizadas nas membranas dos tilacóides, e apresentam alta sensibilidade às espécies reativas de oxigênio, produzidas na fase fotoquímica da fotossíntese. O dano às membranas acarreta um acúmulo de energia, e alteração no potencial redox. $O$ fato de não haver água suficiente para fornecer elétrons ao fotossistema, afeta o transporte de elétrons envolvendo a proteína D2, que mantém 
sua estrutura ligada a plastoquinona $Q A$, que transfere elétrons da feofitina até a QB (BISWAL, 2011).

A energia luminosa absorvida pelas moléculas de clorofila pode ser direcionada para três possíveis vias: aproximadamente $80-90 \%$ da energia absorvida é utilizada na fase fotoquímica da fotossíntese; 5-15\% é dissipada na forma de calor e $0,5-2 \%$ é refletida na forma de luz vermelha ou vermelho-distante, que é a chamada fluorescência da clorofila a (MAXWELL \& JOHNSON, 2000). Em condições de estresse, a conversão quântica da fotossíntese diminui, enquanto a emissão de calor e a fluorescência da clorofila aumentam consideravelmente (GUÉRA et al., 2004), e isso se reflete na diminuição dos valores de eficiência potencial dos fotossistemas, apresentada pelas plantas em suspensão de irrigação, quando comparadas as plantas controle.

O aumento da fotoinibição reflete um aumento gradativo do acúmulo de espécies reativas de oxigênio que podem causar estresse oxidativo. A análise bioquímica e das enzimas antioxidantes trazem informações importantes a respeito da atividade das enzimas do sistema de defesa e seu papel na resposta ao déficit hídrico. Nesse experimento, verificou-se um pico de atividade da enzima SOD um dia após a suspensão de irrigação, fato que pode representar um mecanismo inicial de sinalização das plantas contra a falta de água (DJOUKENG et al., 2008).

Verificou-se também um novo aumento de atividade da SOD após 8DSI e 1DRE (Tabela 2). Existem muitos relatos de que em várias espécies vegetais há um aumento da atividade da SOD em resposta a diversos fatores estressantes, sendo por isso considerada importante na tolerância ao estresse (BROETTO et al., 2002). A SOD tem um papel importante na tolerância da planta, pois atua na primeira linha de defesa contra a toxicidade causada pelo acúmulo das espécies reativas de oxigênio geradas pelo excesso de energia ou por danos nas membranas celulares. Posteriormente, atua catalisando a dismutação de radicais superóxido $\left(\mathrm{O}^{2-}\right)$ em peróxido de hidrogênio $\left(\mathrm{H}_{2} \mathrm{O}_{2}\right)$ e oxigênio $\left(\mathrm{O}_{2}\right)$, representando assim, um dos principais mecanismos de defesa contra o estresse oxidativo celular, causado pelo déficit e posterior estresse hídrico (CATANEO, 2008).

TABELA 2: Atividade das enzimas antioxidantes de plantas de soja em regime de suspensão de irrigação; As atividades da Superóxido Dismutase (SOD), Peroxidase (POD) e Catalase (CAT) foram normalizadas e comparadas às das plantas controle (irrigação normal), no período de 13 a 22 de março de 2014.

\begin{tabular}{cccc} 
Data & SOD $(\mathrm{U} / \mathrm{mg}$ proteína) & $\mathrm{POD}(\mu \mathrm{mol} / \mathrm{min} / \mathrm{mg}$ prot. $)$ & CAT $(\mathrm{mKat} / \mu \mathrm{g} \mathrm{prot})$. \\
\hline 0 DSI & 1,08 & 0,84 & 1,21 \\
1 DSI & $1,33^{*}$ & 0,80 & 1,23 \\
2 DSI & 0,96 & 0,98 & 1,08 \\
3 DSI & 1,04 & 0,90 & 1,38 \\
4 DSI & 0,99 & 0,96 & 1,12 \\
5 DSI & 1,00 & 0,96 & $1,30^{*}$ \\
6 DSI & 0,97 & $1,18^{*}$ & $2,12^{*}$ \\
7 DSI & 0,98 & $1,27^{*}$ & $4,01^{*}$ \\
8 DSI & $1,18^{*}$ & $1,24^{*}$ & $2,75^{*}$ \\
1 DRE & $1,19^{*}$ & $1,16^{*}$ & $2,15^{*}$ \\
\hline
\end{tabular}

* Diferença significativa quando comparada ao tratamento controle, a $5 \%$ de probabilidade segundo teste Tukey. DSI: Dias Sem Irrigação, DRE: Dia da Re-irrigação.

As enzimas CAT e POD apresentaram atividade significativamente maior nas plantas em IS em relação ao controle a partir de 5 e 6DSI, respectivamente. Esses dados indicam que as plantas em suspensão de irrigação apresentaram inicio de 
estresse oxidativo devido à falta de água, pois as peroxidases e catalases são as mais importantes enzimas reguladoras dos níveis intercelulares de $\mathrm{H}_{2} \mathrm{O}_{2}$ por toda a planta (Furlan et al., 2012). A maior atividade da POD também se deve ao fato de ela atuar na prevenção e proteção aos efeitos deletérios causados por radicais livres e pela peroxidação dos lipídios, resultantes do estresse hídrico sofrido pelas plantas (BLOKHINA et al., 2003). Sabe-se que uma produção maciça de ROS, não controlada pelos mecanismos antioxidantes, pode induzir entre outras coisas degradação dos pigmentos fotossintéticos e das membranas do tilacóide, e alteração na estrutura e função de proteínas (URANO et al., 2009), sendo esses danos cada vez maiores conforme o aumento da intensidade e duração do período de estresse, explicando assim a perda de eficiência quântica do FSII, acompanhada de aumento da atividade do sistema antioxidante das plantas sem irrigação.

A análise das imagens térmicas obtidas no experimento mostrou que a partir de 1DSI, as plantas sem irrigação apresentavam temperaturas médias no solo dos vasos significativamente maiores em relação ao controle. No entanto pode-se observar que as temperaturas foliares apresentaram valores significativamente maiores a partir de 2DSI (Tabela 3), bem antes do aparecimento de resposta das variáveis bioquímicas e fotossintéticas.

TABELA 3: Temperaturas médias foliares, do solo e $\Delta T$, calculados utilizando imagens térmicas acompanhadas de software da câmera de imagens térmicas FLIR. Fotos tiradas as 12:00 h, no período de 12 a 22 de março de 2014. CO: Controle, mudas com irrigação constante; IS: mudas com irrigação suspensa de 14 a 21/03/14.

\begin{tabular}{|c|c|c|c|c|c|c|}
\hline & \multicolumn{2}{|c|}{$\begin{array}{l}\text { Temperatura do Solo } \\
\left({ }^{\circ} \mathrm{C}\right)\end{array}$} & \multicolumn{2}{|c|}{$\begin{array}{c}\Delta T^{\circ} \\
\left(T^{\circ} C_{a r}-T^{\circ} C_{\text {folha }}\right)\end{array}$} & \multicolumn{2}{|c|}{$\begin{array}{l}\text { Temperatura Foliar } \\
\left({ }^{\circ} \mathrm{C}\right)\end{array}$} \\
\hline & $\mathrm{CO}$ & IS & $\mathrm{CO}$ & IS & $\mathrm{CO}$ & IS \\
\hline $0 \mathrm{DSI}$ & $29,73 \mathrm{a}$ & $27,44 a$ & 1,611 & 1,996 & $27,90 \mathrm{a}$ & $27,52 \mathrm{a}$ \\
\hline $1 \mathrm{DSI}$ & $28,49 \mathrm{a}$ & $27,74 \mathrm{a}$ & 1,311 & 2,176 & 28,48 a & $27,61 \mathrm{a}$ \\
\hline $2 \mathrm{DSI}$ & $29,51 \mathrm{a}$ & $30,45 \mathrm{a}$ & 1,211 & $-0,289$ & $28,20 \mathrm{~b}$ & $29,70 \mathrm{a}$ \\
\hline $3 \mathrm{DSI}$ & $29,90 \mathrm{a}$ & $29,58 \mathrm{a}$ & 0,649 & $-0,571$ & $28,28 b$ & 29,93 a \\
\hline $4 \mathrm{DSI}$ & $28,09 \mathrm{~b}$ & $30,36 \mathrm{a}$ & 2,555 & $-0,045$ & $27,10 \mathrm{~b}$ & $29,65 \mathrm{a}$ \\
\hline $5 \mathrm{DSI}$ & $28,81 \mathrm{~b}$ & $30,66 \mathrm{a}$ & 1,412 & $-0,089$ & $27,81 \mathrm{~b}$ & $29,22 \mathrm{a}$ \\
\hline 6 DSI & $28,32 \mathrm{~b}$ & $33,12 \mathrm{a}$ & 1,279 & -0.941 & $27,81 \mathrm{~b}$ & $30,03 a$ \\
\hline $7 \mathrm{DSI}$ & $28,78 \mathrm{~b}$ & $33,28 \mathrm{a}$ & 2,108 & $-0,897$ & $27,38 \mathrm{~b}$ & $30,38 \mathrm{a}$ \\
\hline $8 \mathrm{DSI}$ & $30,34 \mathrm{~b}$ & $33,90 \mathrm{a}$ & 0,643 & $-2,458$ & $28,81 \mathrm{~b}$ & $31,91 \mathrm{a}$ \\
\hline $1 \mathrm{DRE}$ & $30,64 \mathrm{a}$ & $30,03 \mathrm{a}$ & 0,229 & 0,359 & $29,56 \mathrm{a}$ & $29,43 \mathrm{a}$ \\
\hline
\end{tabular}

* Médias seguidas da mesma letra não diferem significativamente entre os tratamentos, a $5 \%$ de probabilidade segundo Tukey. DSI: Dias Sem Irrigação, DRE: Dia da Re-irrigação.

As temperaturas foliares médias mantiveram-se maiores nas mudas sem irrigação até o dia anterior ao retorno da irrigação, quando as plantas não irrigadas apresentavam temperaturas médias foliares cerca de $3^{\circ} \mathrm{C}$ acima das médias das plantas controle. Observou-se que com o retorno da irrigação as plantas que estavam em IS apresentaram diminuição das temperaturas foliares, atingindo valores semelhantes às plantas do tratamento controle. A relação entre a temperatura da folha e estresse hídrico em plantas tem sido alvo de alguns estudos na literatura (JONES et al., 2009; PAPDI et al., 2009). Reiterando assim o potencial do uso de imagens térmicas para monitorar o status de água das plantas. De fato, imagens térmicas podem mostrar diferenças visuais mais precisas e acuradas entre plantas irrigadas e não irrigadas e até mesmo entre diferentes intensidades de irrigação (BERNI et al., 2009; PADHI et al., 2012; ZARCO-TEJADA et al., 2012). 
A temperatura do ambiente permaneceu em torno dos $29{ }^{\circ} \mathrm{C}$ durante todo $\mathrm{o}$ experimento. Utilizando então os dados de temperatura obtidos, do ambiente e das plantas, foi estimada a diferença entre a temperatura do ambiente e a temperatura foliar $(\Delta \mathrm{T})$ (Tabela 3 ), que pode ser usado como uma estimativa global da dissipação de calor latente pelas plantas (SOUZA et al., 2004). $\mathrm{O} \Delta \mathrm{T}$ das plantas em suspensão de irrigação apresentou valor negativo a partir de 2 DSI, permanecendo assim até o dia anterior ao retorno da irrigação (8DSI), quando os valores de $\Delta \mathrm{T}$ voltaram a ser positivos novamente. As plantas controle não apresentaram valores negativos de $\Delta T$ durante a condução do experimento, não apresentando, portanto, temperaturas médias foliares maiores que a temperatura do ambiente.

Os resultados negativos de $\Delta T \quad(\Delta T<0)$ indicam perda da capacidade dissipativa da planta, mostrando aquecimento da superfície foliar em relação à temperatura do ar, enquanto valores positivos $(\Delta T>0)$ resultam em plantas com uma maior e adequada eficiência dissipativa (SOUZA et al., 2004). Os resultados mostram claramente que a utilização das imagens térmicas pode ser uma importante ferramenta para diagnosticar e prevenir o estresse hídrico severo em plantas. As imagens mostraram que antes do inicio da suspensão da irrigação não havia diferenças visuais entre as temperaturas foliares e de solo de ambos os tratamentos (Figura 1A). A partir de 2DSI, as plantas do tratamento com irrigação suspensa apresentavam temperaturas foliares médias maiores que as plantas controle (Figura 1B), contudo a maior diferença visual pode ser notada com relação às temperaturas do solo.

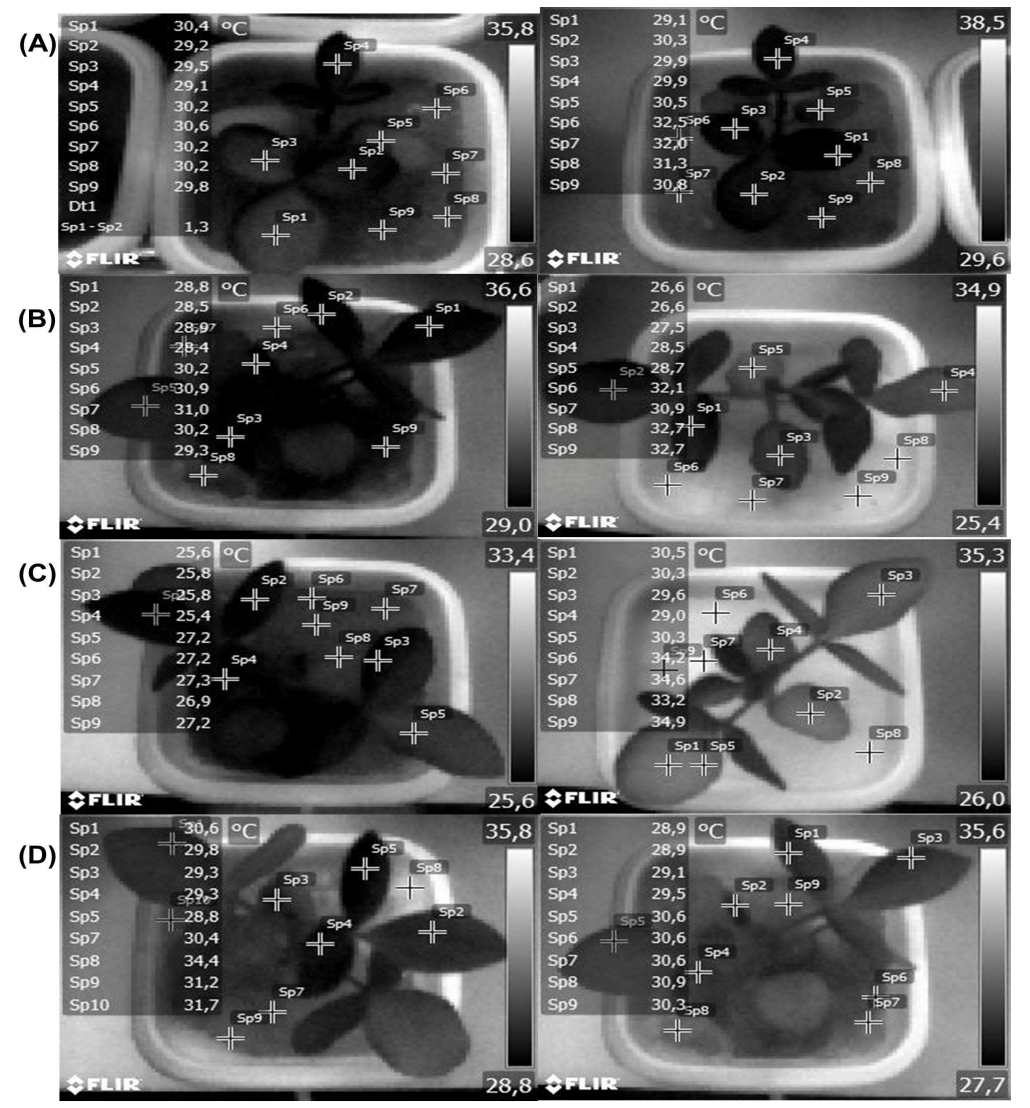

FIGURA 1: Imagens térmicas das plantas de soja obtidas utilizando câmera FLIR antes da suspensão da irrigação (A) em IS, 2 DSI (B), 6 DSI (C), dia anterior ao retorno da irrigação nas plantas em IS e no DRE (D).

*DSI: Dias Sem Irrigação; DRE: Dia da Re-irrigação. Cada ponto da imagem corresponde a uma temperatura $\left({ }^{\circ} \mathrm{C}\right)$ correspondente na planta e no solo. No lado esquerdo da imagem observam-se as mudas para controle e no lado direito mudas em IS. 
A maior diferença visual entre os tratamentos pode ser percebida nas imagens obtidas após 6DSI, dois dias antes do retorno da irrigação das plantas em IS (Figura 1C). Desse modo fica claro o potencial uso das imagens térmicas nos estudos fisiológicos com plantas em condições de estresse. Há trabalhos que relatam o uso de imagens térmicas no monitoramento da qualidade de produtos hortícolas (KRANNEr et al., 2010), saúde de transplantes e qualidade da união nos processos de enxertia ou até mesmo detectar um estresse antes que os sintomas sejam visíveis (CHAERLE et al., 2009). Outro fato importante, é que as temperaturas médias do solo também apresentaram uma grande diferença visual, tornaram-se maiores que as temperaturas do controle a partir de 4DSI (Tabela 3), ficando esta diferença visível já nas imagens obtidas com 2DSI (Figura 1B). O monitoramento da temperatura do solo se torna importante também, à medida que a temperatura do solo influencia no desempenho e produtividade das plantas, por influenciar diretamente nas taxas de evapotranspiração.

\section{CONCLUSÃO}

A partir dos dados coletados e analisados, conclui-se que a utilização das imagens térmicas pode ser uma ferramenta eficiente, não destrutiva, de monitoramento e prevenção de estresse hídrico severo e de monitoramento e manejo hídrico. As imagens mostraram diferenças entre os tratamentos irrigados e em suspensão de irrigação antes do agravamento do estresse, e antes mesmo de que as plantas exibissem uma maior perda da capacidade dissipativa de calor e maiores danos ao aparato fotossintético.

\section{REFERÊNCIAS}

BERNI, J. A. J.; ZARCO-TEJADA, P. J.; SUÁREZ, L.; FERERES, E. Thermal And Narrowband Multispectral Remote Sensing For Vegetation Monitoring From An Unmanned Aerial Vehicle. Transactions On Geoscience And Remote Sensing, v.47, p.722-738, 2009.

BISWAL, B. P. N.; JOSHI, M. K.; RAVAL, U. C. BISWAL, Photosynthesis, a global sensor of environmental stress in green plants: stress signaling and adaptation, Current Science, v.101, p.47-56, 2011.

BOARD, J. E. (Org). A comprehensive survey of international soybean researchgenetcs, physiology, agronomy and nitrogen relationships. InTech, 613p, 2013.

BOR, M.; ÖZDEMIR, F.; TÜRKAN, I. The effect of salt stress on lipid peroxidation and antioxidants in leaves of sugar beet Beta vulgaris $\mathrm{L}$. and wild beet Beta maritima $\mathrm{L}$. Plant Science, Limerick, v.164, p.77-84, 2003.

BLOKHINA, O.; VIROLAINEN, E.; FAGERSTEDT, K. V. Antioxidants, oxidative damage and oxygen deprivation stress: a review. Annals of Botany, London, v.91, n.2, p.179-194, 2003. 
BRADFORD, M. M. A Rapid And Sensitive Method For Quantification Of Microgran Quantities Of Protein Utilizing The Principle Of Protein-Dye-Binding. Anal, Biochem., v.72, p.248-254, 1976.

BROETTO, F.; LUTTGE, U.; RATAJCZAK, R. Influence of ligth intensity and salt treatment on mode of photosyntesis and enzymes of the antioxidatives response system of Mesembryanthemum crystallium, functional. Plant Biology, Victoria, v.29, p.13-23, 2002.

CATANEO, A. C. Métodos espectrofotométricos para a determinação de enzimas relacionadas ao estresse em material vegetal. Material didático, Não paginado, 2008.

CHAERLE L.; LENK, S.; LEINONEN, I.; JONES, H. G.; VAN DER STRAETEN, D.; BUSCHMANN, C. Multi-sensor plant imaging: towards the development of a stresscatalogue. Biotechnology Journal, v.4, p.1152-1167, 2009.

DJOUKENG, J. D.; ARBONA, V.; ARGAMASILLA, R.; GOMEZ-CADENAS, A. Flavonoid Profiling In Leaves Of Citrus Genotypes Under Different Environmental Situations Flavonoid Profiling In Leaves Of Citrus Genotypes. J. Agric. Food Chem., v.56, p.11087-11097, 208.

FARIAS, J. R. B.; NEPOMUCENO, A. L.; NEUMAIER, N. Ecofisiologia da soja. Londrina: Embrapa-CNPSo, Circular Técnica, v. 48, p.9, 2007.

FEDOROFF, N. V.; BATTISTI, D. S.; BEACHY, R. N.; ET AL. Radically rethinking agriculture for the 21st century. Science, v.327, p.833-834, 210.

FRANCHINI, J. C.; DEBIASI, H.; SACOMAN, A.; NEPOMUCENO, A. L.; FARIAS, J. R. B. Manejo do solo para redução das perdas de produtividade pela seca. Londrina, EMBRAPA SOJA, 2009.

FURLAN, A.; LLANES, A.; LUNA, V.; CASTRO, S. Physiological and biochemical responses to drought stress and subsequent rehydration in the symbiotic association peanut-Bradyrhizobium sp. ISRN Agronomy, Article ID 318083. doi:10.5402/2012/318083, 2012.

GUÉRA, A.; CALATAYUD, A.; SABATER, B.; BARRENO, E. Involvement Of The Thylakoidal NADH-Plastoquinone-Oxidoreductase Complex In The Early Responses To Ozone Exposure Of Barley (Hordeum Vulgare L.) Seedling. J. Exp. Bot, v.56, p.205-218, 2004.

HETHERINGTON A. M.; WOODWARD I. The Role Of Stomata In Sensing And Driving Environmental Change. Nature, v.424, p.901-908, 2003.

HOSSAIN, Z.; LÓPEZ-CLIMENT, M. F.; ARBONA, V.; PÉREZ-CLEMENTE, R. M.; GÓMEZ-CADENAS, A. Modulation Of The Antioxidant System In Citrus Under Waterlogging And Subsequent Drainage. J. Plant Physiol., v.166, p.1391-1404, 2009. 
JALEEL, C.A.; MANIVANNAN, P.; WAHID, A.; FAROOQ, M.; AL-JUBURI, H. J.; SOMASUNDARAM, R.; PANNEERSELVAM, R. Drought Stress In Plants: A Review On Morphological Characteristics And Pigments Composition. International Journal Of Agriculture \& Biology, v.11, p.100-105, 2009.

JONES, H. G.; SERAJ, R.; LOVEYS, B. R.; XIONG, L. WHEATON, A.; PRICE, A. H. Thermal infrared imaging of crop canopies for the remote diagnosis and quantification of plant responses to water stress in the field, Functional Plant Biology, v.36, p.978-979, 2009.

KIRAKOSYAN, A.; KAUFMAN, P.; WARBER, S.; ZICK, S.; AARONSON, K.; BOLLING, S.; CHUL CHANG, S. Applied Environmental Stresses To Enhance The Levels Of Polyphenolics In Leaves Of Hawthorn Plants. Physiol. Plant., v.121, p.182-186, 2009.

KRANNER, I.; KASTBERGER, G.; HARTBAUER, M.; PRITCHARD, H. W. Noninvasive diagnosis of seed viability using infrared thermography. Proceedings of the National Academy of Sciences, USA, v.107, p.3912-3917, 2010.

KUMAR, A.; LI, C.; PORTIS A. R. JR. Arabidopis thaliana expressing a thermostable chimeric Rubisco activase exhibits enhanced growth and higher rates of photoeynthesis at moderately high temperatures. Photosynth Res, v.100, p.143153, 2009.

LISAR, S. Y. S.; MOTAFAKKERAZAD, R.; HOSSAIN, M. M. \& RAHMAN, I. M. M. Water Stress In Plants: Causes, Effects And Responses. In: Rahman, I. M. M. \& Hasegawa, H. Water Stress, Intech, Croatia, p.01-14, 2012.

LEE, J. D.; SHANNON, J. G.; VUONG, T. D.; MOON, H.; NGUYEN, H. T.; TSUKAMOTO, C.; CHUNG, G. Genetic diversity in wild soybean (Glycine sojaSieb, and Zucc.) accessions from southern island of Korean peninsula. Plant Breeding, v.129, p.257-263, 2010.

MAES, W. H.; STEPPE, K. Estimating evapotranspiration and drought stress with ground-based thermal remote sensing in agriculture: a review. Journal of Experimental Botany, v.63, p.4671-4712, 2012.

MAXWELL, K.; JOHNSON, G. N. Chlorophyll Fluorescence - A Practical Guide. J. Exp. Bot, n.51, p.659-668, 2000.

MELOTTO, M.; UNDERWOOD, W.; HE, S.Y. Role of stomata in plant innate immunity and foliar bacterial diseases. Annual Review of Phytopathology, v.46, p.101-122, 2008.

PAPDI C.; JOSEPH, M. P.; SALAMO, I. P.; VIDAL, S.; SZABADOS, L. Genetic technologies for the identification of plant genes controlling environmental stress responses. Functional Plant Biology, v.36, p.696-720, 2009. 
PADHI, J.; MISRA, R. K.; PAYERO, J. O. Estimation Of Soil Water Deficit In An Irrigated Cotton Field With Infrared Thermography. Field Crops Research, n.126, p.45-55, 2012.

SOUZA. G. M.; VILLA NOVA, N. A.; \& GONÇALVES, A. N. Entropy, information and water stress in Eucaliptus camaldulensis in vitro. Rev. Bras. Biol., v.59, p.471-476, 1999.

SOUZA, G. M.; RIBEIRO, R. V.; SANTOS, M. G.; RIBEIRO, H. L.; OLIVEIRA, R. F. Approximate entropy as a measure of complexity in sap flow temporal dynamics of two tropical tree species under water deficit. Anais da Academia Brasileira de Ciências, v.76(3), p.625-630, 2004.

SOUZA, G. M.; CATUCHI, T. A.; BERTOLLI, S. C.; SORATTO, R. P. Soybean Under Water Deficit: Physiological and Yield Responses. In: Board. E. J. (Org). A comprehensive survey of international soybean research-genetcs, physiology, agronomy and nitrogen relationships. InTech, v.1, p.273-299, 2013.

TEISSEIRE H.; V. GUY, Copper-Induced Changes In Antioxidant Enzymes Activities In Fronds Of Duckweed (Lemna Minor), Plant Science, n.153, p.65-72, 2000.

URANO, K.; MARUYAMA, K.; OGATA, Y.; MORISHITA, Y.; TAKEDA, M.; SAKURAI, N.; SUZUKI, H.; SAITO, K.; SHIBATA, D.; KOBAYASHI, M. Characterization Of The ABA-Regulated Global Responses To Dehydration In Arabidopsis By Metabolomics. Plant Journal, n.57, p.1065-1078, 2009.

ZARCO-TEJADA, P. J.; GONZÁLEZ-DUGO, V.; BERNI, J. A. J. FLUORESCENCE. Temperature And Narrow-Band Indices Acquired From A UAV Platform For Water Stress Detection Using A Micro-Hyperspectral Imager And A Thermal Camera. Remote Sensing Of Environment, n.117, p.322-337, 2012. 